\title{
Influence of Nanocrystalline Palladium Morphology on Alkaline Oxygen Reduction Kinetics
}

\author{
Eliran Hamo ${ }^{\dagger}$, Avichay Raviv ${ }^{\dagger}$ and Brian A. Rosen * ${ }^{(D)}$ \\ Department of Materials Science and Engineering, Tel Aviv University, Ramat Aviv 69978001, Israel \\ * Correspondence: barosen@post.tau.ac.il \\ + Authors with equal contribution.
}

Received: 30 May 2019; Accepted: 24 June 2019; Published: 26 June 2019

\begin{abstract}
The structure sensitivity of the alkaline oxygen reduction reaction (ORR) on palladium is of great interest as cost considerations drive the need to find a replacement for platinum catalysts. The kinetics of alkaline ORR were investigated on nanocrystalline palladium (Pd) films with domain sizes between 14 and $30 \mathrm{~nm}$ that were synthesized by electrodeposition from aqueous electrolytes. Ten Pd films were prepared under varying electrodeposition parameters leading to each having a unique texture and morphology. The sensitivity of initial alkaline ORR kinetics to the Pd surface structure was evaluated by measuring the kinetic current density and number of electrons transferred for each film. We show through scanning electron microscopy (SEM), x-ray diffraction (XRD), atomic force microscopy (AFM), and voltammetry from rotating disc electrodes (RDEs) that the fastest alkaline ORR kinetics are found on Pd surfaces with high surface roughness, which themselves are composed of fine grains. Such a study is useful for developing membrane electrode assemblies (MEAs) based on directly electrodepositing catalyst onto a conductive diffusion layer.
\end{abstract}

Keywords: Pd thin films; electrocatalysis; electrodeposition

\section{Introduction}

Broad fuel cell commercialization efforts can be frustrated by prohibitively high costs and insufficient durability, which is attributed mainly to challenges in catalyst development [1]. Compared to the acidic polymer electrolyte membrane fuel cell (PEMFC), alkaline fuel cells show relatively fast kinetics for the oxygen reduction reaction (ORR). Consequently, the development of platinum-free cathodes for alkaline fuel cells has been of great interest owing to the high cost and limited availability of platinum (Pt) [2-5]. Palladium (Pd), as a pure metal, is a good candidate to substitute for $\mathrm{Pt}$ cathodes in alkaline membrane fuel cells (AMFCs), as its performance as a catalyst for ORR in alkaline media exceeds its performance in acidic media [6]. A recent study on the relationship between alkaline ORR catalytic activity and the metal d-band center showed that $\operatorname{Pd}(111)$-terminated nanoparticles and nano-Pd/C both had a d-band center value close to $\mathrm{Pt}(111)$-terminated nanoparticles and $\mathrm{Pt} / \mathrm{C}$ respectively, suggesting that $\mathrm{Pd}$ may offer a viable replacement for $\mathrm{Pt}$ in fuel cells $[7,8]$. Pd mining resources are also comparable to those for platinum; typically 2-3 fold less expensive than Pt.

It is well understood that the structure of the catalytic surface can play just as significant a role in the observed kinetic rate as the atomic composition [9-11]. The focus of developing Pt-free cathodes has therefore been redirected in the last 10 years towards elucidating the structural sensitivity of catalysts used in commercial fuel cells. These studies generally fall into one of two categories: polished single crystal surfaces or faceted nanoparticles whose faces are terminated by a single crystallographic plane (e.g., (100)-terminated FCC nanoparticles will make cube [12,13]). While polished single crystal surfaces are easily characterized and reproducible, they do not represent a realistic catalyst system. Alternatively, faceted nanoparticles more closely resemble commercial catalysts; however, it is difficult 
to identify structural variations between individual particles over such a large scale. As opposed to structural studies of $\mathrm{Pt}$ and $\mathrm{Pd}$ in acidic electrolytes $[9,14,15]$, the role of Pd structure on alkaline ORR kinetics remains unclear.

Erikson et al. report that $5 \mathrm{~nm}$ (100)-terminated Pd nanocubes outperformed their polycrystalline spherical counterparts, leading them to conclude that a structural sensitivity existed and $\operatorname{Pd}(100)$ was the most active plane [12]. By contrast, Shao et al. reported no structural dependence between $\operatorname{Pd}(100)$-terminated cubes and $\operatorname{Pd}(111)$-terminated octahedra, although it should be noted that the nanoparticles in the this study were reported to be $27 \mathrm{~nm}, 5$ times larger than the Erikson study [16]. Such a conflict is representative of the lack of clarity for evaluating the structural dependence of Pd on alkaline ORR kinetics. Work from Jiang et al. suggested that the structural difference may be due to a size dependence rather than preferred orientation. They report a 3-fold increase in alkaline ORR kinetics as the nanoparticle size increased from 3 to $16 \mathrm{~nm}$ [17].

By comparison to single-crystal and nanoparticle studies of alkaline ORR activity, the use of electrodeposition of nanocrystaline films is less studied, but an emerging method for building fuel cell membrane electrode assemblies (MEA). Using this method, the catalyst is directly electrodeposited onto the gas diffusion layer (GDL) and is then hot-pressed in contact with the ionically conductive membrane [18]. Here, we employ pulse and direct current electrodeposition from aqueous electrolytes to synthesize nanocrystalline Pd films with varying roughness and morphology. Structural sensitivity is evaluated by comparing the average structural properties of each film to its alkaline ORR performance.

\section{Results and Discussion}

\subsection{Sample Preparation}

Pd films having various morphologies and textures were prepared by electrodeposition onto gold disc electrodes using either direct current (DC) or pulse current (PC) electrodeposition. In the case of PC deposition, the peak current density and duty cycle were varied. The duty cycle is defined as the percentage of the total pulse width where the current is on. A summary of the samples prepared for this study is shown in Table 1. All surfaces were prepared at room temperature and limited to a total charge of $1.5 \mathrm{C} / \mathrm{cm}^{2}$.

Table 1. Deposition parameters for controlling Pd film morphology.

\begin{tabular}{|c|c|c|c|}
\hline $\begin{array}{l}\text { Peak Current Density } \\
{\left[\mathrm{mA} / \mathrm{cm}^{2}\right]}\end{array}$ & $\begin{array}{l}\text { Direct Current (DC) or } \\
\text { Pulse Current (PC) } \\
\text { Deposition }\end{array}$ & Pulse Width (ms) & $\begin{array}{l}\text { ECSA }\left(\mathrm{cm}^{2}\right)+\mathrm{Pd}-\mathrm{O} \\
\text { Reduction }\end{array}$ \\
\hline 30 & PC; $20 \%$ duty cycle & 100 & 0.280 \\
\hline 30 & PC; $35 \%$ duty cycle & 100 & 0.261 \\
\hline 30 & PC; $50 \%$ duty cycle & 100 & 0.199 \\
\hline 3 & DC & - & 0.384 \\
\hline 3 & PC; $20 \%$ duty cycle & 100 & 0.690 \\
\hline 3 & PC; $35 \%$ duty cycle & 100 & 0.417 \\
\hline 3 & PC; $50 \%$ duty cycle & 100 & 0.480 \\
\hline 10 & DC & - & 0.423 \\
\hline 20 & DC & - & 0.494 \\
\hline 30 & DC & - & 0.608 \\
\hline
\end{tabular}

† The geometric surface area of the gold disc was $0.196 \mathrm{~cm}^{2}$. 


\subsection{Electrochemical Surface Area Characterization}

After electrodeposition, the electrochemical surface area (ECSA) of the Pd film was calculated by measuring the charge required to reduce a monolayer of palladium oxide in a method similar method to the one reported for Pd-Cu alloy films [19]. Briefly, a cyclic voltammogram was taken in an $\mathrm{N}_{2}$-saturated $0.1 \mathrm{M} \mathrm{HClO}_{4}$ electrolyte between $0.4 \mathrm{~V}$ vs. the reversible hydrogen electrode (RHE) and a variable positive inversion potential. This inversion potential was varied and plotted against the charge associated with palladium oxide reduction. At the inversion potential associated with the formation of a single monolayer of palladium oxide (1.544 V vs. RHE), a slope change is observed (Figure S1) representing the transition between monolayer and multilayer formation. The ECSA was calculated by Equation (1) at this inversion potential where $Q_{M}$ is the charge required to reduce a monolayer of palladium oxide.

$$
\operatorname{ECS} A\left[\mathrm{~cm}^{2}\right]=\frac{Q_{M}[C] \times 10^{6}}{405\left[\frac{C}{\mathrm{~cm}^{2}}\right]}
$$

Previous reports have shown that the repeated formation and reduction of palladium oxides can impact the surface roughness through the formation of multi-dimensional defects such as grain boundaries and clusters of adatoms, zero-dimensional defects such as vacancies, as well as drive atomic rearrangement [20]. Since this the ECSA measurement procedure involved the 1-time formation of an oxide monolayer and its subsequent reduction, the modulation of the surface roughness via the formation of the monolayer oxide is believed to be minimal. Alternative methods for measuring the ECSA include evaluation of the hydrogen stripping region, and the removal of a copper $(\mathrm{Cu})$ monolayer placed on top of palladium by underpotential deposition (UPD).

It is well known that the hydrogen region on palladium electrodes exhibits poor definition, mostly due to the fact that hydrogen is both adsorbed and absorbed owing to its high solubility. Figure S2 shows the cyclic voltammograms, including the hydrogen adsorption/desorption regions, for the samples prepared in this work. Since it was difficult to unambitiously define the hydrogen region on our Pd films, the ECSA values using this procedure are not reported. Cu UPD has also been previously used to define the ECSA of both polycrystalline and single crystal electrodes [21-23]. Consistent with these reports, this technique was found to give ECSA values $150 \%-200 \%$ larger than that of the other methods. Furthermore, in polycrystalline Pd films, structural determination from $\mathrm{Cu}$ UPD is difficult to extract because the contribution of the different planes to the atomic arrangement of the surface is not known. In consideration of the above and the fact that the reduction of Pd-O gave the most reproducible results, we report ECSA values using this technique in Table 1.

\subsection{Structural Characterization of Pd Films}

Scanning electron microscopy (SEM) images were taken to show how changing palladium electrodeposition parameters gave rise to different morphologies. Figure 1 shows a series of Pd films that were deposited at $3 \mathrm{~mA} / \mathrm{cm}^{2}$ at various duty cycles. All surfaces appeared to be compact and have a needle-like morphology.

By comparing Figure $1 \mathrm{a}-\mathrm{d}$, it is shown that the needle-like characteristic became enhanced as the duty cycle increased from $20 \%$ to $100 \%$ (DC). Figure 2 shows SEM micrographs of Pd films electrodeposited at $30 \mathrm{~mA} / \mathrm{cm}^{2}$ at various duty cycles. It is clear that the morphology of these samples differed from those deposited at $3 \mathrm{~mA} / \mathrm{cm}^{2}$. As the duty cycle increased, the morphology of the film transitioned from a coalesce (globular) structure to a faceted structure. 

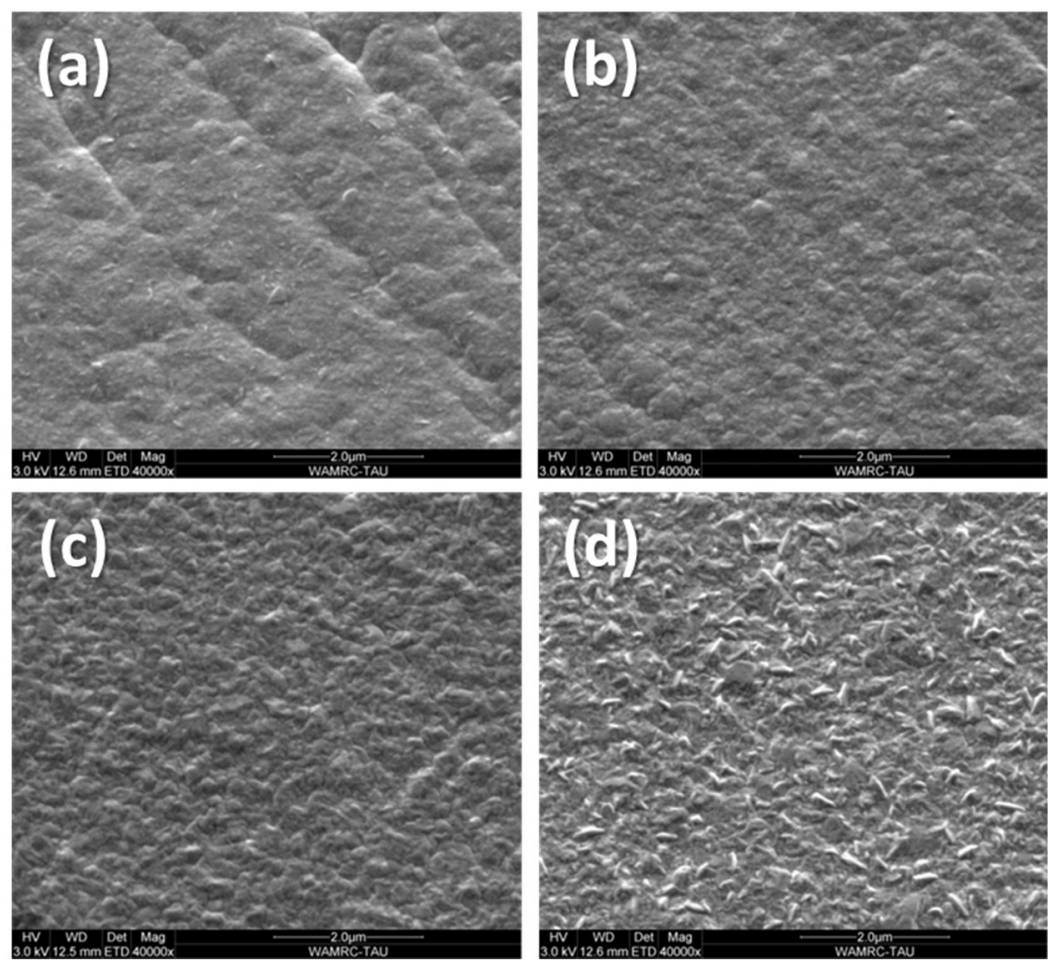

Figure 1. Scanning electron microscopy (SEM) images of Pd films deposited at $3 \mathrm{~mA} / \mathrm{cm}^{2}$ (a) $20 \%$ duty cycle (b) $35 \%$ duty cycle (c) $50 \%$ duty cycle (d) DC (100\% duty cycle).
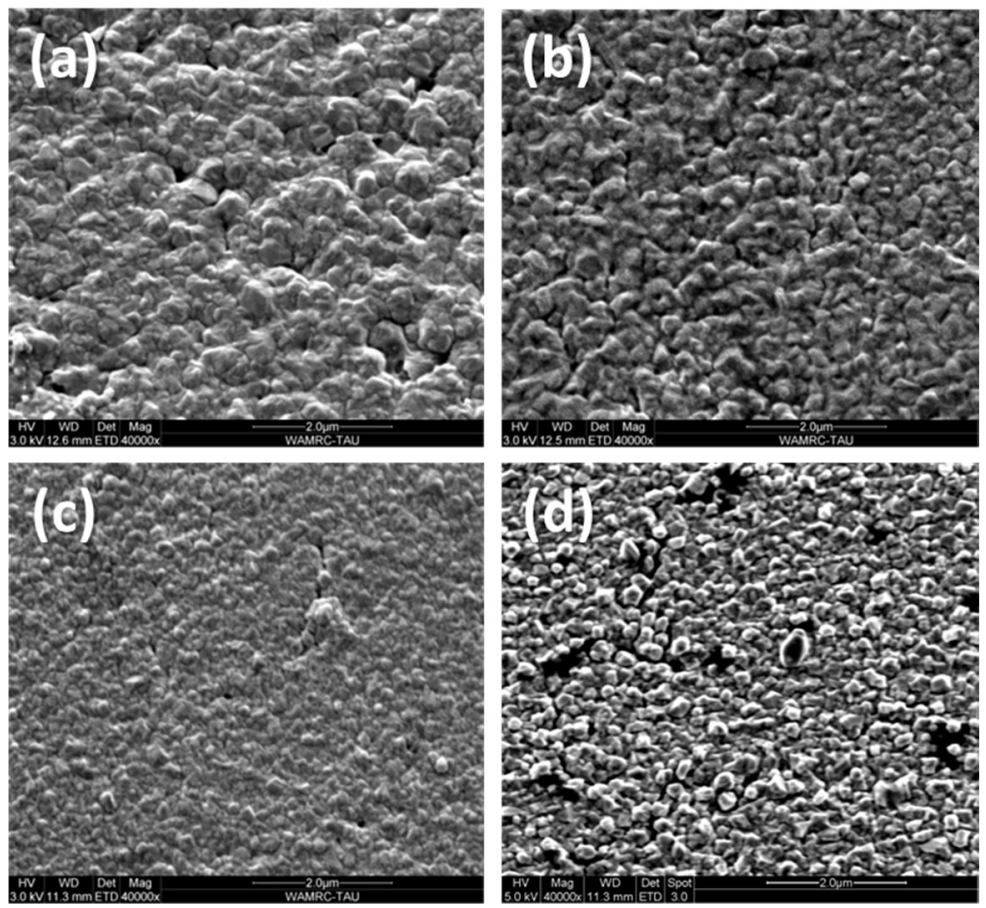

Figure 2. Scanning electron microscope (SEM) images of Pd films deposited at $30 \mathrm{~mA} / \mathrm{cm}^{2}$ (a) $20 \%$ duty cycle (b) $35 \%$ duty cycle (c) $50 \%$ duty cycle (d) DC (100\% duty cycle).

Pd-films prepared by DC electrodeposition at $10 \mathrm{~mA} / \mathrm{cm}^{2}, 20 \mathrm{~mA} / \mathrm{cm}^{2}$ appeared to have a faceted morphology similar to the $30 \mathrm{~mA} / \mathrm{cm}^{2}$ DC sample (Figure S3). In all cases, films deposited at above $10 \mathrm{~mA} / \mathrm{cm}^{2}$ were less compact compared to films deposited at $3 \mathrm{~mA} / \mathrm{cm}^{2}$. Morphology changes observed in Figures 1 and 2 are related to the sensitivity of the nucleation and crystallization processes to the depletion of Pd ions in the boundary layer adjacent to the gold disc. Both the current density and the duty 
cycle therefore served to modulate the mass-transfer and kinetics of Pd film electrodeposition [24,25]. When growth is the dominant mechanism, the surface consists of large and course deposits whereas when the nucleation processes dominate, the surface is smooth. Assuming the limiting current density is not exceeded, DC deposition is expected to yield smaller crystallites compared to PC deposition at the same average current density because grain growth takes place during the relaxation time. For instance, the Pd film deposited at $10 \mathrm{~mA} / \mathrm{cm}^{2}$ under DC conditions and the one deposited at $30 \mathrm{~mA} / \mathrm{cm}^{2}$ with a duty cycle of $35 \%$ both had an average current density of $\sim 10 \mathrm{~mA} / \mathrm{cm}^{2}$, yet the PC sample gave grains $\sim 35 \%$ larger.

When the pulse limiting current density for Pd deposition in this electrolyte $\left(18.2 \mathrm{~mA} / \mathrm{cm}^{2}\right.$, Figure S4) was exceeded, as was the case for Pd films prepared at 20 and $30 \mathrm{~mA} / \mathrm{cm}^{2}$, side reactions including hydrogen evolution, local changes in $\mathrm{pH}$, and a thicker diffusion layer all served to interrupt and impede growth, giving rise to smaller crystallites. The replenishment of Pd ions during the relaxation time increased the instantaneous limiting current density achievable using PC deposition compared to the limiting current density observed in DC deposition [26]. Therefore, decreasing the duty cycle (increasing the relaxation time) served to increase the pulse limiting current density and reduced the occurrence of processes serving to interrupt growth. This in turn led to larger crystallites with decreasing duty cycle.

\subsection{Alkaline ORR Characterization}

The electrochemical reduction of $\mathrm{O}_{2}$ on nanocrystalline $\mathrm{Pd}$ films was studied in oxygen-saturated $0.1 \mathrm{M} \mathrm{KOH}$ solutions using rotating disk electrodes. Figure 3a shows a characteristic cathodic linear sweep voltammograms (LSV) starting from $1 \mathrm{~V}$ to $0.3 \mathrm{~V}$ vs. RHE at $10 \mathrm{mV} / \mathrm{s}$ at different rotation rates. Although only the Pd film deposited at DC $10 \mathrm{~mA} / \mathrm{cm}^{2}$ is shown here, this figure is representative of all Pd films in this study. The remaining plots are shown in (Figures S5-S7).
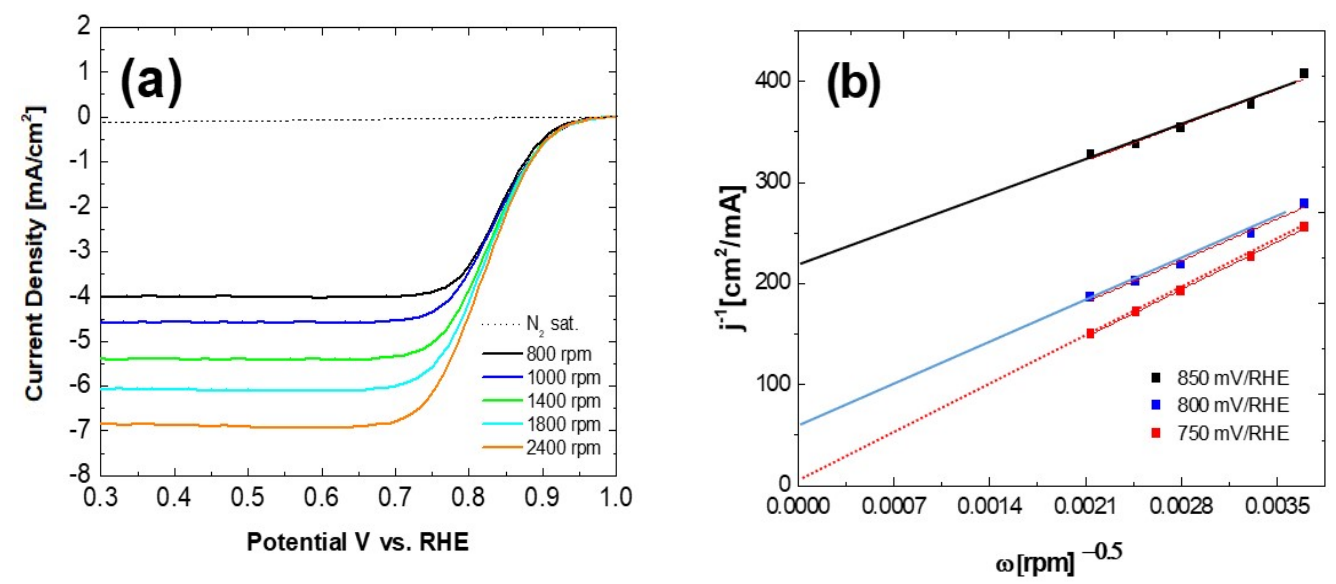

Figure 3. (a) ORR polarization curves for the Pd film prepared at $10 \mathrm{~mA} / \mathrm{cm}^{2} \mathrm{DC}$ at different rotation speeds, scan rate $10 \mathrm{~mA} / \mathrm{s}$ (b) Koutecky-Levich plot for Pd film deposited at $10 \mathrm{~mA} / \mathrm{cm}^{2} \mathrm{DC}$.

The RDE data was fit to the Koutecky-Levich (K-L) equation (Equation (2))

$$
\frac{1}{j}=\frac{1}{j_{k}}+\frac{1}{j_{l}}=\frac{1}{j_{k}}+\frac{1}{0.62 n F A D_{0}^{2 / 3} v^{-1 / 6} C^{*} \omega^{1 / 2}}
$$

where $j$ is the current density, $j_{k}$ is the kinetic current density, $j_{l}$ is the limiting current density, $\mathrm{F}$ is $96,484.56 \mathrm{C} \mathrm{mol}^{-1}, \mathrm{n}$ is the number of electrons transferred, $\mathrm{A}$ is the area in $\mathrm{cm}^{2}$, D is the diffusion coefficient of $\mathrm{O}_{2}$ in $\mathrm{cm}^{2} \mathrm{~s}^{-1}, \mathrm{C}^{*}$ is the bulk concentration of $\mathrm{O}_{2}$ in $\mathrm{mol} \mathrm{cm}{ }^{-3}, v$ is kinematic viscosity in $\mathrm{cm}^{2} \mathrm{~s}^{-1}$, and $\omega$ is the rotation rate in rpm. The coefficients used for $0.1 \mathrm{M} \mathrm{KOH}$ electrolyte at $30^{\circ} \mathrm{C}$ were: $\mathrm{D}=1.9 \times 10^{-5} \mathrm{~cm}^{2} \mathrm{~s}^{-1}, \mathrm{C}^{*}=1.1 \times 10^{-6} \mathrm{~mol} \mathrm{~cm}^{-3}$, and $v=1.3 \times 10^{-2} \mathrm{~cm}^{2} \mathrm{~s}^{-1}$ [27]. Figure $3 \mathrm{~b}$ shows 
that the fit to Equation (2) at 750, 800, and $850 \mathrm{mV}$ vs. RHE is linear, indicating first-order kinetics with respect to molecular oxygen. Koutecky-Levich fitting for the remaining samples are shown in Figures S8-S10. The initial kinetic current density for alkaline ORR, $\mathrm{j}_{\mathrm{k}}$, a characteristic indicator of the reaction's kinetics, is derived from the slope of the fitted lines [6].

\subsection{Effect of Pd Morphology and Texture on Alkaline ORR Kinetics}

In order to characterize the relationship between alkaline ORR kinetics and structure sensitivity, key structural parameters including morphology, weighted grain size, and roughness factor (electrochemical surface area divided by geometrical area) were correlated with the initial kinetics of alkaline oxygen reduction as characterized by the sample's kinetic current density and number of electrons transferred.

To better visualize these relationships, 2D meshes were created, where the axes are two selected descriptions of the surface, and the color map displays the kinetic variable. Figure 4 shows how the number of electrons transferred and the kinetic current density varied with weighted grain size and roughness factor at $750 \mathrm{mV}$ vs. RHE. The weighed grain size is the sum total of the grain size of each Pd crystal orientation multiplied by the relative abundance of that orientation.

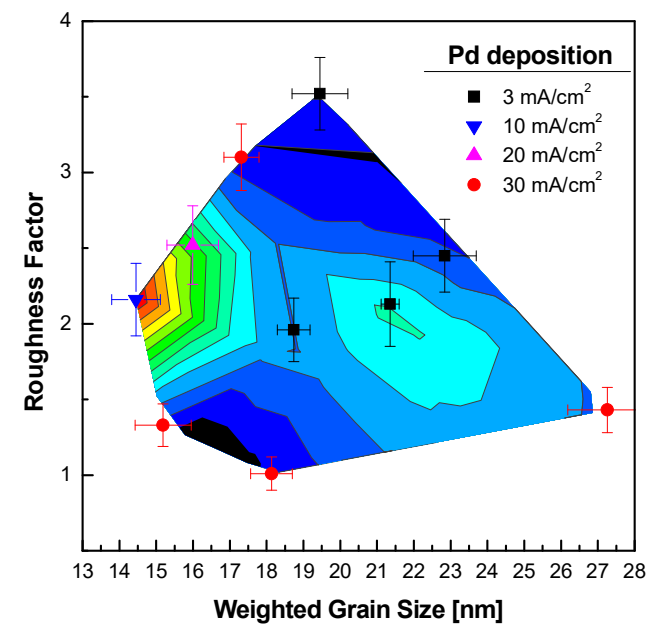

ORR

\# electrons

(a)

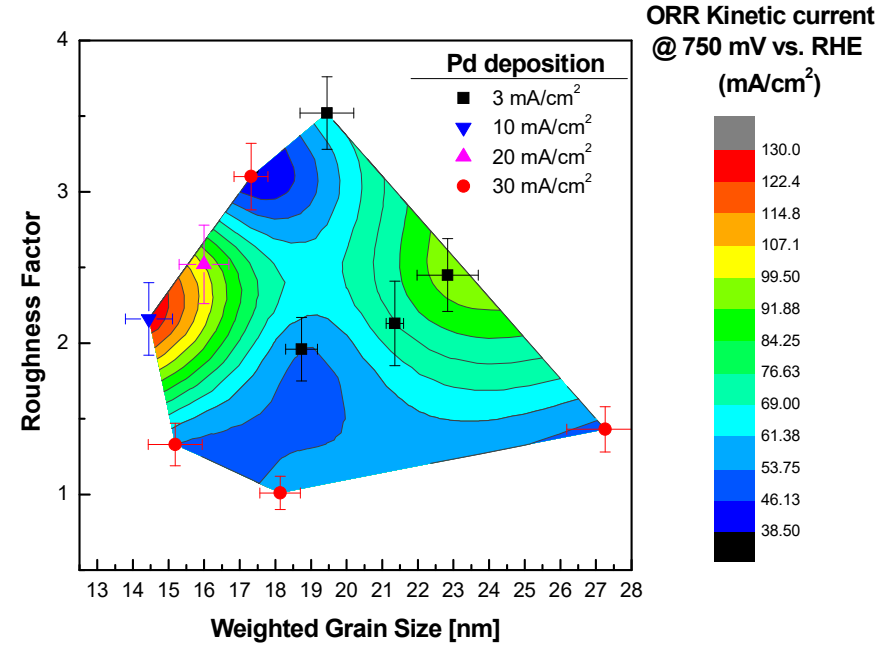

(b)

Figure 4. (a) Number of electrons transferred and (b) kinetic current density and number of electrons at $750 \mathrm{mV}$ vs. RHE as function of the weighted grain size and roughness factor. 
As the weighted grain size decreased, both the kinetic current density and number of electrons transferred increased. This trend can be explained by the fact that smaller grains necessarily lead to a larger density of grain boundaries. Grain boundaries can often break the translation symmetry in the direction perpendicular to the contact interface. This gives rise to strongly localized electronic states in the vicinity of the grain boundary and to the redistribution of the electronic charge density, making the electron density less uniform. The non-uniformity of charge distribution in the neighborhood of grain boundaries may be considered as a type of dangling bond stimulating the charge transfer from the substrate to the adsorbate, thereby enhancing adsorption and reaction kinetics [28].

At a fixed grain size, a local maximum is observed in the kinetic current density as the roughness factor is varied. Such a "volcano" behavior may be indicative of how surface roughness influences the $\mathrm{Pd}-\mathrm{O}$ bond strength and therefore reduction kinetics via Sabatier's principle [29]. From Figure 4, we conclude that both the roughness factor and the weighted grain size influence the kinetic current density and the oxygen reduction mechanism (via the number of electrons transferred).

The mixed contribution of film morphology and microtexture is visualized in Figure 5. The morphology of the Pd film is defined by SEM images shown earlier as being either compact needle-like, coalesce, or faceted. Although the kinetic current density does not globally increase in a linear fashion with decreasing grain size, the impact of grain size on the kinetic current density appears more linear when comparing between samples of the same morphology.

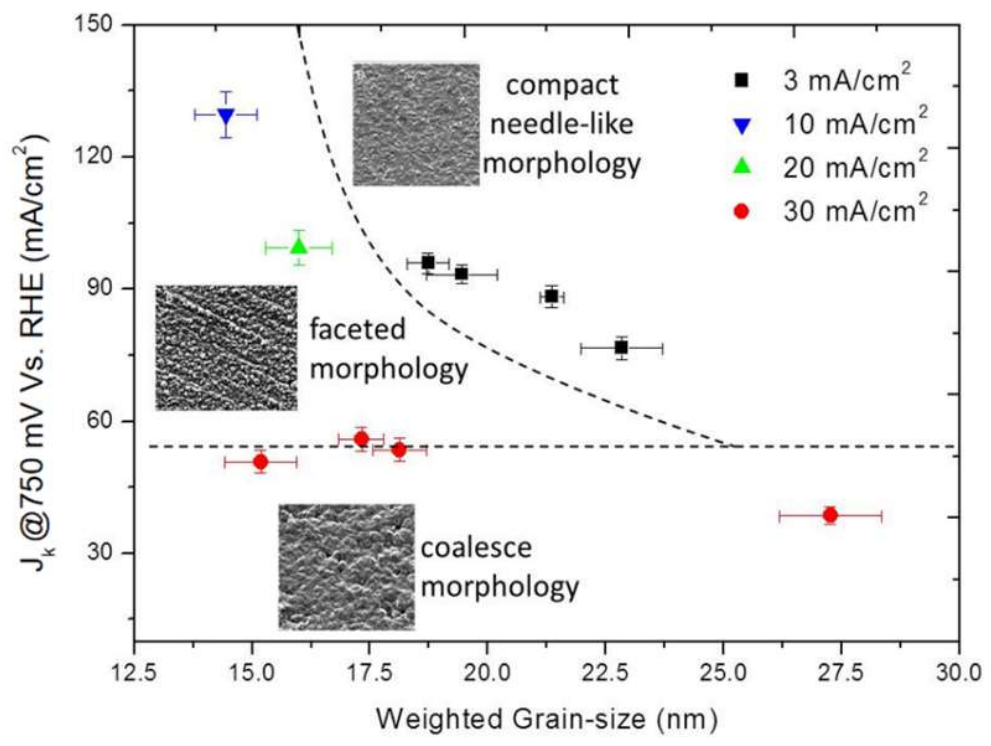

Figure 5. Structural phase diagram showing the kinetic current density at $750 \mathrm{mV}$ vs. RHE as function of weighted grain size and morphology.

Atomic force microscopy (AFM) shown in Figure 6 was used to distinguish between the different morphological groups by their average surface roughness $\left(S_{a}\right)$ evaluated over the complete 3D surface [30]. Mathematically, $S_{a}$ is defined as:

$$
S_{a}=\frac{1}{A} \iint_{a}|Z(x, y)| d x d y
$$

where larger values of $S_{a}$ indicate rougher surfaces.

The faceted morphology had the largest $S_{a}$ value $(0.588 \mu \mathrm{m})$, meaning it has the roughest surface. As expected, the compact needle-like morphology had the lowest $S_{a}(0.179 \mu \mathrm{m})$, and coalesce gave an intermediate $S_{a}$ value between the faceted and compact values $(0.271 \mu \mathrm{m})$. 

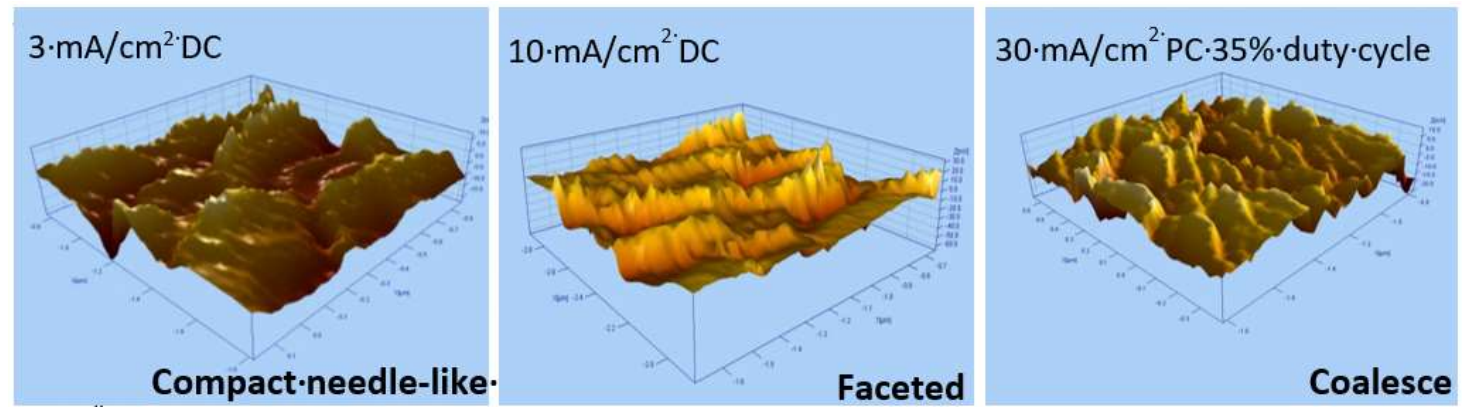

Figure 6. Atomic force microscopy (AFM) maps of needle-like, faceted, and coalesce domains in the Pd film.

\section{Experimental}

\subsection{Electrochemistry}

Cyclic voltammetry (CV) was carried out using a rotating disk electrode (RDE) in $0.1 \mathrm{M} \mathrm{KOH}$ (Merck Co) placed inside a jacketed three-electrode cell. All electrolytes were kept at $303 \mathrm{~K}$ by a heated bath recirculator. The electrolyte was purged with $\mathrm{N}_{2}$ or $\mathrm{O}_{2}$ by flowing $120 \mathrm{sccm}$ of the appropriate gas through a glass frit placed in the electrolyte for $30 \mathrm{~min}$. Electrochemical control was through a BioLogic VSP-300 potentiostat. After electropolishing, linear sweep voltammograms (LSV) were taken from $1 \mathrm{~V}$ to $0.3 \mathrm{~V}$ vs. RHE at a scan rate of $10 \mathrm{mV} / \mathrm{s}$ at varying rotation speeds $(0,800,1000,1400,1800$, and $2400 \mathrm{rpm}$ ). Reported LSV curves are the fifth is a series of five consecutively acquired LSVs in order to ensure a stable profile.

\subsection{Materials Characterization}

Scanning electron microscopy (SEM) (ThermoFisher, Waltham, MA, USA),) micrographs were taken by a Quanta 200 FEG (field-emission gun) Environmental Scanning Electron Microscope (ESEM) operated in high-vacuum mode. The sample stage was tilted to $20^{\circ}$ during sample examination in order to minimize capacitance effects. The electron beam voltage was at $3.5 \mathrm{keV}$. Atomic force microscopy (AFM, PicoSPMTM, Molecular Imaging) was used to image the surfaces in air. Imaging was done by using tips made of $\mathrm{Si}_{3} \mathrm{~N}_{4}$ (Veeco) in contact-mode. Following the image processing, surface roughness parameters were calculated with the aid of SPIPTM software.

Analysis of the grain size in the Pd films were characterized using the D8 Advance diffractometer (Bruker, Karlsruhe, Germany) using Cu Ka1 radiation $(\mathrm{k}=1.540562)$. XRD patterns were collected from $2 \Theta$ of $20^{\circ}$ to $110^{\circ}$ at a scan speed of $1.0 / \mathrm{min}$ and at a grazing incident angle of $2^{\circ}$ to minimize the contribution from the gold substrate. Although the grain size measured by XRD is measured perpendicular to the surface, grain size measurements from electron backscatter diffraction (EBSD) parallel to the surface were found to be in good agreement with XRD.

\section{Conclusions}

Electrodeposited nanocrystalline Pd films were shown to be active for ORR in alkaline media. The influence of electrodeposition parameters was found to influence the surface morphology and weighed grain size, resulting in Pd surfaces displaying different ORR kinetics. The influence of grain size and surface roughness were found to have a profound impact on the reduction of oxygen. This is likely due to the impact of grain boundaries on oxygen adsorption. In practice, we find that ORR kinetics can be maximized by depositing a surface that has both a large surface roughness and composed of a fine-grained structure with many grain boundaries. Within the range of parameters observed, the Pd film that performed the best was deposited at DC $10 \mathrm{~mA} / \mathrm{cm}^{2}$. By contrast, the film that performed the worst was the one prepared at $30 \mathrm{~mA} / \mathrm{cm}^{2} \mathrm{PC}$ and $20 \%$ duty cycle owing to its large grains and smooth morphology. 
Supplementary Materials: The following are available online at http://www.mdpi.com/2073-4344/9/7/566/s1, Figure S1. (a) Cyclic voltammograms at several inversion potential ( $E_{\text {inv }}$ in the inset) for the $20 \mathrm{~mA} / \mathrm{cm}^{2} \mathrm{DC}$ sample with $\mathrm{N}_{2}$ saturated $\mathrm{H}_{2} \mathrm{SO}_{4}(0.5 \mathrm{M})$ solution. Scan rate of $50 \mathrm{mV} / \mathrm{s}$. The arrow indicating the Pd reduction peak. (b) Plot of the oxide reduction charge against the inversion potential (Einv) for the $20 \mathrm{~mA} / \mathrm{cm}^{2} \mathrm{DC}$ sample. The intercept between the lines stands for the charge for an oxide monolayer reduction. Figure S2: Cyclic voltammetry showing the hydrogen region for each of the Pd films in $0.5 \mathrm{M} \mathrm{H}_{2} \mathrm{SO}_{4}$ at a sweep rate of $10 \mathrm{mV} / \mathrm{s}$. Figure S3. ESEM images of Pd films deposited at (a) $10 \mathrm{~mA} / \mathrm{cm}^{2} \times 40 \mathrm{k}$ (B) $20 \mathrm{~mA} / \mathrm{cm}^{2} \times 40 \mathrm{k}$. Figure S4. Linear sweep voltammetry of gold electrode in the Pd deposition solution, limiting current density is reached at $18.2 \mathrm{~mA} / \mathrm{cm}^{2}$. Figure S5. polarization curves of ORR at different rotation speed, scan rate:10 mA/s: (A) $3 \mathrm{~mA} / \mathrm{cm}^{2} 20 \%$ duty cycle (B) 3 $\mathrm{mA} / \mathrm{cm}^{2} 35 \%$ duty cycle (C) $3 \mathrm{~mA} / \mathrm{cm}^{2} 50 \%$ duty cycle (D) $3 \mathrm{~mA} / \mathrm{cm}^{2} \mathrm{DC}$. Figure S6. polarization curves of ORR at different rotation speed, scan rate: $10 \mathrm{~mA} / \mathrm{s}$ : (A) $30 \mathrm{~mA} / \mathrm{cm}^{2} 20 \%$ duty cycle (B) $30 \mathrm{~mA} / \mathrm{cm}^{2} 35 \%$ duty cycle (C) $30 \mathrm{~mA} / \mathrm{cm}^{2} 50 \%$ duty cycle (D) $30 \mathrm{~mA} / \mathrm{cm}^{2}$ DC. Figure S7. polarization curves of ORR at different rotation speed, scan rate: $10 \mathrm{~mA} / \mathrm{s}$ : (A) $10 \mathrm{~mA} / \mathrm{cm}^{2}$ DC (B) $20 \mathrm{~mA} / \mathrm{cm}^{2}$ DC. Figure S8. K-L plots of each sample replotted at different voltages: (A) $3 \mathrm{~mA} / \mathrm{cm}^{2} 20 \%$ duty cycle (B) $3 \mathrm{~mA} / \mathrm{cm}^{2} 35 \%$ duty cycle (C) $3 \mathrm{~mA} / \mathrm{cm}^{2} 50 \%$ duty cycle (D) $3 \mathrm{~mA} / \mathrm{cm}^{2}$ DC. Figure S9. K-L plots of each sample replotted at different voltages: (A) $30 \mathrm{~mA} / \mathrm{cm}^{2} 20 \%$ duty cycle (B) $30 \mathrm{~mA} / \mathrm{cm}^{2} 35 \%$ duty cycle (C) $30 \mathrm{~mA} / \mathrm{cm}^{2} 50 \%$ duty cycle (D) $30 \mathrm{~mA} / \mathrm{cm}^{2}$ DC. Figure S10. K-L plots of each sample replotted at different voltages: (A) $10 \mathrm{~mA} / \mathrm{cm}^{2} \mathrm{DC}$ (B) $20 \mathrm{~mA} / \mathrm{cm}^{2} \mathrm{DC}$.

Author Contributions: B.A.R. and E.H. conceived and designed the experiments; E.H. and A.R. performed the experiments; E.H. and A.R. analyzed the data; B.A.R. drafted the paper with critical comments from the other authors.

Funding: This research received no external funding.

Acknowledgments: The authors would like to acknowledge the support of the Planning \& Budgeting Committee/ISRAEL Council for Higher Education (CHE) and Fuel Choice Initiative (Prime Minister Office of ISRAEL), within the framework of "Israel National Research Center for Electrochemical Propulsion" (INREP).

Conflicts of Interest: The authors declare no conflict of interest.

\section{References}

1. Gasteiger, H.A.; Kocha, S.S.; Sompalli, B.; Wagner, F.T. Activity benchmarks and requirements for Pt, Pt-alloy, and non-Pt oxygen reduction catalysts for PEMFCs. Appl. Catal. B Environ. 2005, 56, 9-35. [CrossRef]

2. Shao, M. Palladium-based electrocatalysts for hydrogen oxidation and oxygen reduction reactions. J. Power Sour. 2011, 196, 2433-2444. [CrossRef]

3. Henning, S.; Herranz, J.; Gasteiger, H.A. Bulk-Palladium and Palladium-on-Gold Electrocatalysts for the Oxidation of Hydrogen in Alkaline Electrolyte. J. Electrochem. Soc. 2015, 162, F178-F189. [CrossRef]

4. Durst, J.; Siebel, A.; Simon, C.; Hasché, F.; Herranz, J.; Gasteiger, H.A. New insights into the electrochemical hydrogen oxidation and evolution reaction mechanism. Energy Environ. Sci. 2014, 7, 2255-2260. [CrossRef]

5. Sheng, W.; Bivens, A.P.; Myint, M.; Zhuang, Z.; Forest, R.V.; Fang, Q.; Chen, J.; Yan, Y. Non-precious metal electrocatalysts with high activity for hydrogen oxidation reaction in alkaline electrolytes. Energy Environ. Sci. 2014, 7, 1719-1724. [CrossRef]

6. Srejic, I.; Rakocevic, Z.; Nenadovic, M.; Strbac, S. Oxygen reduction on polycrystalline palladium in acid and alkaline solutions: Topographical and chemical Pd surface changes. Electrochim. Acta 2015, 169, $22-31$. [CrossRef]

7. Lima, F.H.B.; Zhang, J.; Shao, M.H.; Sasaki, K.; Vukmirovic, M.B.; Ticianelli, E.A.; Adzic, R.R. Catalytic Activity-d-Band Center Correlation for the O2 Reduction Reaction on Platinum in Alkaline Solutions. J. Phys. Chem. C 2007, 111, 404-410. [CrossRef]

8. Shao, M.-H.; Sasaki, K.; Adzic, R.R. Pd-Fe Nanoparticles as Electrocatalysts for Oxygen Reduction. J. Am. Chem. Soc. 2006, 128, 3526-3527. [CrossRef]

9. Marković, N.; Adzic, R.R.; Cahan, B.D.; Yeager, E.B. Structural effects in electrocatalysis: Oxygen reduction on platinum low index single-crystal surfaces in perchloric acid solutions. J. Electroanal. Chem. 1994, 377, 249-259. [CrossRef]

10. Poirier, J.A.; Stoner, G.E. Microstructural Effects on Electrocatalytic Oxygen Reduction Activity of Nano-Grained Thin-film Platinum in Acid Media. J. Electrochem. Soc. 1994, 141, 425-430. [CrossRef]

11. Yoon, Y.-G.; Park, G.G.; Yang, T.H.; Han, J.N.; Lee, W.Y.; Kim, C.S. Effect of pore structure of catalyst layer in a PEMFC on its performance. Int. J. Hydrog. Energy 2003, 28, 657-662. [CrossRef] 
12. Erikson, H.; Merisalu, M.; Rähn, M.; Sammelselg, V.; Tammeveski, K. Electrochemical reduction of oxygen on palladium nanocubes in acid and alkaline solutions. Electrochim. Acta 2012, 59, 329-335. [CrossRef]

13. Marks, L.; Peng, L. Nanoparticle shape, thermodynamics and kinetics. J. Phys. Condens. Matter 2016, 28, 53001. [CrossRef] [PubMed]

14. Markovic, N.M.; Gasteiger, H.A.; Ross, P.N. Oxygen reduction on platinum low-index single-crystal surfaces in alkaline solution: Rotating ring diskPt (hkl) studies. J. Phys. Chem. 1996, 100, 6715-6721. [CrossRef]

15. Kondo, S.; Nakamura, M.; Maki, N.; Hoshi, N. Active sites for the oxygen reduction reaction on the low and high index planes of palladium. J. Phys. Chem. C 2009, 113, 12625-12628. [CrossRef]

16. Shao, M.; Odell, J.; Humbert, M.; Yu, T.; Xia, Y. Electrocatalysis on shape-controlled palladium nanocrystals: Oxygen reduction reaction and formic acid oxidation. J. Phys. Chem. C 2013, 117, 4172-4180. [CrossRef]

17. Jiang, L.; Hsu, A.; Chu, D.; Chen, R. Size-dependent activity of palladium nanoparticles for oxygen electroreduction in alkaline solutions. J. Electrochem. Soc. 2009, 156, B643-B649. [CrossRef]

18. Litster, S.; McLean, G. PEM fuel cell electrodes. J. Power Sour. 2004, 130, 61-76. [CrossRef]

19. Fouda-Onana, F.; Bah, S.; Savadogo, O. Palladium-copper alloys as catalysts for the oxygen reduction reaction in an acidic media I: Correlation between the ORR kinetic parameters and intrinsic physical properties of the alloys. J. Electroanal. Chem. 2009, 636, 1-9. [CrossRef]

20. Grdeń, M.; Łukaszewski, M.; Jerkievicz, G.; Czerwiński, A. Electrochemical behaviour of palladium electrode: Oxidation, electrodissolution, and ionic adsorption. Electrochim. Acta 2009, 53, 7583-7598.

21. Mayet, N.; Servat, K.; Kokoh, B.; Napporn, T.W. Probing the Surface of Noble Metals Electrochemically by Underpotntial Depostion of Transition Metals. Surfaces 2019, 2, 257-276. [CrossRef]

22. Chierchie, T.; Mayer, C. Voltammetric study of the underpotential depostion of copper on polycrystalline and sing crystal palladium surfaces. Electrochim. Acta 1988, 33, 341-345. [CrossRef]

23. Shao, M.; Odell, J.H.; Choi, S.; Xia, Y. Electrochemical surface area measurements of platium- and palladium-based nanoparticles. Electrochem. Commun. 2013, 31, 46-48. [CrossRef]

24. Natter, H.; Hempelmann, R.; Krajewski, T. Nanocrystalline Palladium by Pulsed Electrodeposition. Berichte der Bunsengesellschaft für physikalische Chemie 1996, 100, 55-64. [CrossRef]

25. Fukumoto, Y.; Kawashima, Y.; Hayashi, T. Pulse plating of Pd-Ni alloys: Dependence on current density. Surf. Coat. Tech. 1986, 27, 145-150. [CrossRef]

26. Rosen, B.A.; Gileadi, E.; Eliaz, N. Microstructure and composition of pulse plated Re-Ni alloys on a rotating cylinder electrode. J. Electroanal. Chem. 2014, 731, 93-99. [CrossRef]

27. Xing, W.; Yin, M.; Lv, Q.; Hu, Y.; Liu, C.; Zhang, J. 1-Oxygen Solubility, Diffusion Coefficient, and Solution Viscosity. In Rotating Electrode Methods and Oxygen Reduction Electrocatalysts; Elsevier: Amsterdam, The Netherlands, 2014; pp. 1-31.

28. Crampin, S.; Vvedensky, D.D.; MacLaren, J.M.; Eberhart, M.E. Electronic structure near (210) tilt boundaries in nickel. Phys. Rev. B. 1989, 40, 3413. [CrossRef]

29. Lavacchi, A.; Miller, H.; Vizza, F. Nanotechnology in Electrocatalysis for Energy; Springer: New York, NY, USA, 2013.

30. De Oliveira, R.R.L.; Albuquerque, D.A.C.; Cruz, T.G.S.; Yamaji, F.M.; Leite, F.L. Measurement of the Nanoscale Roughness by Atomic Force Microscopy: Basic Principles and Applications, Atomic Force Microscopy-Imaging, Measuring and Manipulating Surfaces at the Atomic Scale, Victor Bellitto, IntechOpen, doi:10.5772/37583. Available online: https://www.intechopen.com/books/atomic-force-microscopy-imagingmeasuring-and-manipulating-surfaces-at-the-atomic-scale/measurement-of-the-nanoscale-roughness-byatomic-force-microscopy-basic-principles-and-applications (accessed on 26 June 2019).

(C) 2019 by the authors. Licensee MDPI, Basel, Switzerland. This article is an open access article distributed under the terms and conditions of the Creative Commons Attribution (CC BY) license (http://creativecommons.org/licenses/by/4.0/). 